\title{
Liberdades e resistências: as ações de emancipação da mulher e a negação da violência
}

\section{Freedoms and resistances: women's emancipation actions and the denial of violence}

\author{
CECÍLIA PIRES
}

\begin{abstract}
Resumo: Esse texto discute as diversas liberdades que as mulheres conquistaram e exerceram ao longo da história, o que expressa uma formação de consciência e de compreensão como sujeito histórico. Nossa intenção é refletir de que modo as liberdades e resistências corroboraram para a conquista da emancipação e da luta feminista no Brasil e no mundo. Para isso, iremos nos utilizar como referências exemplos de pensadoras, mulheres que lutaram no plano intelectual, contra o pensamento patriarcal e machista, construtor de violências e opressões. Nossa proposta aqui é pensar em dicotomias e universalidades para uma abordagem acerca do tema mulheres.
\end{abstract}

Palavras-chave: Liberdades. Resistências. Mulher. Violência.

Abstract: This paper discusses the various freedoms that women have conquered and exercised throughout history, which expresses a construction of consciousness and understanding their condition as a historical subject. The intention is to reflect on how freedoms and resistances collaborated for the achievement of emancipation and feminist struggle in Brazil and all around the world. For this purpose, there are examples of thinkers, women who fought in a intellectual level, against patriarchal and macho thinking, which is the builder of violence and oppression. The proposal here is to think of dichotomies and universalities for an approach on the theme women.

Keywords: Liberties. Resistances. Woman. Violence.

\section{Para propor o debate}

As liberdades conquistadas e exercidas pelas mulheres expressam o tempo de formação da consciência da própria identidade como sujeito histórico. Além disso, acentuam o sentido de uma luta que não pode ser levada, senão em conjunto com todos os movimentos sociais, sensíveis e comprometidos com a ideia de gênero, emancipação e combate a qualquer forma de opressão. As resistências, por sua vez, refletem o estágio dessas liberdades, ao mesmo tempo que indicam o avanço social, político e econômico das mulheres que chegam à esfera da sociedade civil e às

\footnotetext{
${ }^{1}$ Pós-doutora na área de Filosofia Política em Paris I-Sorbonne. Doutora em Filosofia, na área de Filosofia Social, pela Universidade Federal do Rio de Janeiro (UFRJ). Atuou como Professora e Pesquisadora na Universidade Federal de Santa Maria (UFSM) e na Universidade do Vale do Rio dos Sinos (UNISINOS). É membro do Grupo de Trabalho Ética e Cidadania/ANPOF. Trabalhou como Pesquisadora na área de Filosofia Política. Professora de Teorias da Democracia, no Programa de PósGraduação em Direito na IMED-Passo Fundo. Atualmente, trabalha com Consultorias e Assessorias nas áreas de Ética e Filosofia Política. Mantém uma página profissional no facebook: - Professora de Filosofia. Consultora em Ética e Filosofia Política. Página de acesso: https://www.facebook.com/ceciliaphilos/?pnref=lhc. E-mail: pirescecilia@gmail.com
} 
instâncias do Estado, de modo a demarcar novas contingências e novas reivindicações, como resultantes dos processos de libertação.

As liberdades e resistências incidem sobre estruturas formalizadas, cujas concepções conservadoras, tentam impedir as demandas femininas, numa espécie de maniqueísmo dissimulado. Tal constatação pode ser vista por duplicidade de decisões, de parte de Instituições, sejam públicas ou privadas, quando certo moralismo dogmático e autoritário busca persuadir o imaginário social de que à mulher cabe exercer determinadas funções, e ao homem são designados outros papéis sociais, geralmente mais relevantes.

Partindo desse imaginário social, a forma como se articularam os discursos de gênero prejudicou o processo aproximativo dos demais movimentos aos movimentos de mulheres, senão na totalidade, em parte. A estrutura de um poder forte como o Estado comprometeu ações emancipatórias a serem realizadas pelos movimentos feministas.

Guardadas as devidas proporções, atualmente, ainda verificamos atitudes preconceituosas e arbitrárias contra mulheres protagonistas de lutas específicas, especialmente as que se direcionam no âmbito dos direitos humanos, com ênfase nos direitos das crianças e dos jovens em situações de risco social.

$\mathrm{Na}$ realidade, a emancipação tem que se fundar no pensamento e na ação imbricados num projeto comum alternativo ao da consciência comandada pelos interesses do capital e do mercado. Se a racionalidade se exerce com soberania, as razões que incensam os homens e se apiedam das mulheres são razões preconceituosas, que não poderiam ser evocadas como razões de ciência ou de racionalidade, como costumam ser os discursos que se utilizam da suposta diferença sexual e se denominam discursos científicos, ditos racionais. Tais discursos colocam o masculino como modelo positivo, racional, e a mulher a sua diferença, o negativo, sentimental. O que produz e mantém o preconceito em relação às mulheres e o seu "lugar" de subalternidade dentro dessa estrutura de poder.

Sobre essa relação entre o masculino e o feminino, Simone de Beauvoir observa:

O ódio aos homens leva algumas mulheres a uma recusa de todos os valores reconhecidos por eles, a uma rejeição de tudo o que chamam de "modelos masculinos". Não concordo com isso, já que não acredito que existam qualidades, valores, modos de vida especificamente femininos: isso seria admitir a existência de uma natureza feminina, isto é, aderir a um mito inventado pelos homens para aprisionar as mulheres em sua condição de oprimidas. Para as mulheres, não se trata de afirmar-se como mulheres, mas de tornarse seres humanos com todos os seus direitos. (BEAUVOIR, 1990, p. 497). 
Liberdades e resistências: as ações de emancipação da mulher e a negação da violência

Pensamos que essa racionalidade se orienta na lucidez conquistada pela espécie humana, quando o gênero feminino entrou "pedindo licença”, e, agora, pode ocupar o seu lugar, o seu espaço, como resultado de ações vividas, intervindo na estratégia dos desejos, quase como estratégia de guerra. Se a cultura foi construída a partir de um modelo masculino, embora o feminino tenha participado dessa construção, podemos entender que a condição de propor novas realidades é própria do que entendemos por humanidade. Desta forma, estamos decodificando o mundo conforme nossas compreensões humanas. A espécie humana não se divide entre os que pensam e os que sentem, mas reúne essas características numa síntese entendida como racionalidade.

Desse modo, pensar o feminino implica em pensar em dicotomia, por indicar que o tema sobre mulheres, sobre o feminino, sobre movimentos de mulheres ou mitos feministas sempre ensejam visões e posturas de aceitação e de rechaço, em contraposição ao masculino. Talvez isso se deva ao fato da luta das mulheres não ser compreendida como uma luta específica, necessária, com particularidades próprias, em uma sociedade hierárquica e desigual. Nessa luta, é importante, também, pensar o universal. A universalidade permite compreender o assunto no âmbito de uma significação da humanidade, como espécie e não só como gênero, o que aumentam as dificuldades de análise.

Os diferentes estudos realizados sobre a evolução humana demonstram o trato preconceituoso e reducionista acerca de situações que envolvem paradigmas de racionalidade, destacando diferenças entre razão e paixão, como se o gênero de uma espécie fosse só razão e outro gênero fosse apenas paixão. Essa outra dicotomia agrava a acolhida de assuntos referentes ao tema da mulher, prejudicando a visão de universalidade, em que se contemplam homem e mulher como espécie racional.

\section{Liberdades}

Uma das demandas da emancipação feminina são as referências das diversas liberdades, algumas delas já conquistadas durante este longo processo, ainda em andamento e aparentemente distante de sua conclusão. Dentre as liberdades desejadas e conquistadas, destacamos dois aspectos que consideramos essenciais na história da emancipação feminina: o corpo, como expressão de linguagem e afirmação da subjetividade e o exercício do poder, na esfera pública, quando a mulher assume uma participação cidadã.

Dentre as limitações determinadas pelos imperativos de um ordenamento cultural, o corpo sempre foi tratado como o aspecto menor da condição humana. Toda mortificação religiosa, por exemplo, começa por sacrificar o corpo, como instrumento de pecado, por ser entendido como lugar de desejo. E em se tratando do corpo feminino, a intensidade da agressão sempre foi muito maior, sempre foi visto como destituído da razão, prenhe de desejo. Assim, historicamente, o corpo 
feminino se constituiu como um corpo velado, um corpo escondido, só visível no âmbito doméstico, predestinado a servir aos desejos masculinos e alimentar a prole. As mulheres, que expunham o corpo, eram tratadas como objetos de negócios na relação de mercado, que sempre existiu na humanidade, com as devidas nuances de cada povo, lugar, e momento histórico. Visto como saturado de sexualidade, o corpo feminino era um dos mais legítimos objetos a serem dominados e conduzidos sob vigilância moral.

Pertencem à década de 1960 as primeiras manifestações dos movimentos sociais e de mulheres que expressaram a propriedade do corpo como algo próprio da subjetividade. Na esteira dessa discussão acerca da propriedade do corpo, o sujeito "mulher, esposa e mãe" começa a ser entendido numa compreensão mais alargada de sujeito de consciência pública, capaz de conhecer seus direitos. E, ainda, a erotização do corpo e a estética feminina trazem nova dimensão para a libertação a ser conquistada, a partir de uma auto-compreensão de que eu sou um corpo, eu sou uma linguagem, eu posso me expressar pelo meu corpo, pelo meu universo de desejos.

Acerca desta visão do corpo feminino, enquanto propriedade da mulher, o aborto surge como um dos temas de discussão, mais polêmicos. É um temaproblema a ser enfrentado, com as dificuldades inerentes às questões de natureza moral.

Na luta pela vida como direito de todos, e contra todas as formas de violência, encontramos extrema dificuldade em tratar do assunto. Assim, recorremos à fala de Ivone Bechara para traduzir o que pensamos ser um sentimento razoável acerca das contradições sociais que o tema suscita:

O aborto ainda é crime e criminaliza sempre a mulher, quando, muitas vezes a escolha por fazê-lo não é dela. Sou a favor da descriminalização e da legalização do aborto, porque acho que existem certos problemas que não resolvemos apenas apelando para os bons princípios. O aborto traz uma dor imensa, ou seja, não é uma ação tranquila. Mas deve ser uma opção em certas situações, como em casos de violência, de abuso sexual, e, de maneira especial, em relação às mulheres mais pobres. Esta é uma bandeira que eu levanto [...]. Mas acredite que a problemática do aborto não é tranquila para mim. Por isso, não se pode reduzi-la a um debate entre quem é a favor e quem é contra, por princípio. (BECHARA, 2007, p. 7-8).

A consciência do próprio corpo é uma das dimensões mais significativas da subjetividade e do imaginário feminino. Este aspecto tem uma relevância enorme, uma vez que a mulher desde sempre foi subjugada pelo corpo, entendido como instrumento do pecado. Assim, a infinidade de significados que o corpo produz faz com que desejemos ouvi-lo. Todo corpo tem vozes de promessa, sons de alegria, 
Liberdades e resistências: as ações de emancipação da mulher e a negação da violência

ecos de dores, sinais de alerta, expressões várias de sentimentos e emoções, que se reduzem na expressão linguística de um corpo que se sabe sadio ou doente. Como Merleau-Ponty expressa: o corpo fala.

Assim, o corpo, como expressão de linguagem, tornou-se uma das manifestações libertárias da mulher. O ritmo das falas do nosso corpo e os matizes dessas linguagens são reveladores das nossas vivências, das nossas leituras, dos nossos trabalhos, dos nossos lazeres, das nossas conquistas, das nossas carências, das nossas perdas.

A consciência que adquirimos como sujeitos corporais tem uma eloquência fundante que dinamizou o processo libertário da mulher. O corpo fala, quer ser ouvido e nos permite atitudes corajosas e sábias no conjunto das liberdades a serem efetivadas.

Conforme Eliane Chagas (1995, p. 130):

Nesse sentido, o devir feminino traduz-se também nas relações com o corpo, com a sexualidade, com a sedução e com a estética. Pensar movimentos que resguardem singularidades, conceito tão caro à resistência diária que devemos exercer contra a captura do desejo pela sociedade capitalista, torna-se questão prioritária para o avanço das discussões sobre a mulher.

Esse cuidado e atenção com o corpo é o que nos faz sermos atentos à acolhida, à delicadeza e também ao enfrentamento. Cuidar é garantir equilíbrio, é saber da importância e do valor do que está sendo cuidado. Com isso, o corpo feminino, ao ser assumido como valor, muda o pólo de referência e torna-se motivo de respeito e dignidade. Esta foi uma intensa luta libertária, levada pelas mulheres em suas diversas manifestações.

O exercício do poder, a entrada da mulher na vida pública, é outro movimento da liberdade, cujo enfrentamento, quase uma subversão, exigiu grande esforço da mulher e dos movimentos apoiadores. Mesmo dentro de uma ordem democrática, foram muitas as dificuldades enfrentadas.

Apesar de ainda ser tímida, sabemos que é de extrema importância, a participação da mulher nestes espaços públicos. Ora, as propostas de avanços levadas pelas mulheres à sociedade civil e ao Estado, quando transformadas em leis, permitem que se construa um novo cenário mais nítido da Justiça, além do mero legalismo do ordenamento jurídico. A exemplo disso temos a Lei Maria da Penha, além de outros avanços legais, que não só acolheu as reivindicações das mulheres como demarcou uma história que se constrói como retrato das desigualdades. Entretanto, muitas questões ainda precisam ser resolvidas, como a jornada de trabalho para a mãe nutriz e as creches para a acolhida dos filhos das mulheres trabalhadoras. 
Além disso, ainda há conflitos evidentes nas formas de tratamento dos problemas da mulher, a exemplo das Delegacias especializadas no atendimento feminino, encarregadas de registrar as denúncias e as violências. E, mesmo no âmbito político, ainda aparecem preconceitos advindos de estruturas discricionárias de poder, mesmo no interior de organizações partidárias, que, embora tenham como conquista legal uma proporção de 30\% de candidaturas femininas, nem sempre se evidencia um empenho da própria estrutura partidária para buscar o voto na mulher.

Ora, a representação feminina no e pelo voto foi uma das principais pautas da Primeira Onda Feminista, ainda do século XIX. Emily Darison ${ }^{2}$, inglesa, foi a primeira a reivindicar o direito ao voto, e, num gesto extremo, atirou-se na frente do cavalo de Jorge V. O resultado disso foi o direito ao voto conquistado, em 1918, na Inglaterra.

No Brasil, temos a figura de Bertha Lutz, que fundou, em 1919, a Federação Brasileira para o Progresso Feminino, tendo como um dos principais objetivos a reivindicação pelo voto feminino, conquistado em 1932.

Essas demandas de liberdade conseguem sensibilizar o espaço público. E, em 1975, a ONU declarou o Ano Internacional da Mulher, ocorrendo no México a I Conferência Internacional da Mulher, momento em que as diversas reivindicações femininas encontraram ressonância e acolhida. Ainda que os problemas não tenham sido solucionados ou encaminhados, na totalidade, houve um fórum de debates que marcou significativamente outra ordem social, voltada para as questões das mulheres. Já no Brasil, a Constituição de 1988 representou um marco legal sensível, resultado das conquistas femininas, apoiadas pelos movimentos e partidos de esquerda.

Ainda, eventos como a Eco 92, que teve o espaço "Planeta Fêmea", em que se constituiu a Agenda 21, são sinais concretos da importância de uma congregação de esforços sobre o assunto mulher. Desde 1975, passando pela Conferência de Viena (1993), que avança na questão dos Direitos Humanos, e pela Conferência do Cairo (1994), em que a pauta de temáticas feministas teve um lugar preponderante, ocorre em 1995, no Cairo, a IV Conferência Mundial de Mulheres, em que as mulheres presentes denunciaram as violências sofridas, pedindo liberdade e paz. Assim, abriuse o leque de conquistas libertárias, que garantiram este espaço público, da ação política, como fundamental para a organicidade da luta das mulheres.

\footnotetext{
2 Emily Wilding Davison Blackheath nasceu em Londres no dia 11 de outubro de 1872 Epsom, Surrey, 8 de junho de 1913) foi uma militante do movimento pelo voto feminino na GrãBretanha que, em 4 de junho de 1913, após uma série de ações que foram tanto destrutivas quanto violentas, se jogou em frente ao cavalo do rei Jorge V no Derby Epson Downs, resultando em ferimentos que causaram a sua morte cerebral, formalmente declarada quatro dias depois, mediante insistência da família para um veredito de acidente.
} 
Liberdades e resistências: as ações de emancipação da mulher e a negação da violência

A participação efetiva da mulher nos órgãos de representação popular, seja no Parlamento, seja em Conselhos Governamentais, enseja um olhar de atenção, de cuidado e de continuidade nas reivindicações. Passados 22 anos, o conjunto dos movimentos de mulheres continua denunciando a violência sobre seus corpos e suas vidas, exigindo Justiça e Paz.

A mulher brasileira comparece na cena política de forma participativa, denunciando as discriminações de toda espécie, exigindo equidade de tratamento, respeito às condições de trabalho e retirada de qualquer privilégio de gênero, cor, raça e religião. Isso denota um grau avançado de libertação, se pensarmos nos séculos XIX e XX.

Michelle Perrot, em seus estudos acerca dos excluídos, fala sobre a situação das mulheres:

O século XIX acentua a racionalidade humana da divisão sexual. Cada sexo tem sua função, seus papéis, suas tarefas, seus espaços, seu lugar quase predeterminado, até com seus detalhes. Paralelamente, existe um discurso dos ofícios que faz a linguagem do trabalho uma das mais sexuadas possíveis. "Ao homem, a madeira e os metais. À mulher, a família e os tecidos" declara um delegado operário da exposição mundial de 1867. (PERROT, 1992, p. $178)$.

A divisão sexista continua existindo, mas com menos intensidade e menor rigidez do que no relato de Michelle Perrot. No entanto, a superação dessas determinações, que apresentam uma miopia antropológica, é necessária para que a paisagem da civilização fique menos embaçada.

A libertação feminina, a partir de sua participação nos espaços públicos, é muito difícil. O espaço de poder é extremamente competitivo, e, em muitas situações, a mulher ali está exposta a situação de desamparo e solidão. A exemplo disso, podemos citar o episódio da crise política vivida no Brasil, em 2016, via golpe parlamentar, o que evidenciou o preconceito e o ódio contra o poder feminino. Como resultado do golpe, a Presidente eleita perdeu seu mandato, acusada sem provas, sofreu um julgamento político comandado pelo imperativo categórico da razão machista, e, o que é mais grave, tal razão recebeu a contribuição de votos de mulheres.

\section{Resistências}

As resistências envolvem ação pública conjunta e adoção de estratégias para avanços pretendidos. Ora, a mulher não foi preparada, culturalmente, para o enfrentamento público, embora de forma resistente saiba conviver com as adversidades. 
Todo aparato conceitual acerca da questão da mulher ou das questões do feminino incide numa lógica dual de inclusão e exclusão. Ao falarmos, anteriormente, sobre as liberdades experimentadas, podemos relacioná-las com as resistências resultantes dessas liberdades, destacando o corpo como expressão da linguagem e o poder como afirmação de uma consciência política.

Uma das resistências mais importantes no universo feminino é a resistência ao medo, ou seja, resistir a sentir o medo. Enfrentar o medo e a vergonha que marcou, por longos anos, o imaginário das mulheres foi o que mais contribuiu para sua libertação. O medo se apresenta em vários invólucros, com muitas interfaces. Nem sempre é o medo físico, corporal, embora este esteja sempre presente. No entanto, o medo social, o medo moral e o medo religioso torturaram e tem torturado, por longo tempo, o imaginário feminino. Muitas mulheres resistiram a todos esses medos, protagonizando feitos históricos em seus lugares, países e culturas.

A outra resistência a ser destacada é a da participação pública, cujo traço característico é a entrada da mulher no mundo do trabalho. Até a saída dos muros domésticos, as mulheres temiam tudo e viviam intimidadas pelo medo ou vergonha diante de qualquer exposição pública. Resguardadas no universo familiar, passaram a ser caracterizadas como pessoas limitadas, sem condições de exercer outra função que não fosse a biológica, ofertada por uma ideia metafísica de natureza. A mulher se confundia com um objeto doméstico.

A resistência se dá, então, pelo enfrentamento dos próprios limites. Resistir ao medo de ter medo e resistir à esfera pública como cenário de estranhamento, de não-lugar, fez parte do movimento no qual as mulheres assumiram o seu estar no mundo. Resistir é ter objetivos claros, é buscar interesses conjuntos. Mas o início desse processo foi muito árduo e muitas pereceram.

Ora, a figura mítica de Penélope que tecia um manto, enquanto aguardava o retorno de Ulisses, faz parte desse logos interpretativo da resistência silenciosa e paciente, a qual expressa a astúcia da razão e o desejo diferente da expectativa dos costumes. Tecia o manto e se apressava em desfazê-lo, tarefa em que a paciência e a astúcia se integravam. Penélope urdia seu destino na urdidura do manto ${ }^{3}$. Vivia a plenitude da espera, e isso preenchia o seu silêncio, ao mesmo tempo que a experiência de uma situação limite lhe produzia o temor sobre a incógnita do seu destino, pois nem sempre os deuses são complacentes.

\footnotetext{
${ }^{3}$ Nossa protagonista incomoda-se com a arrogância de seus pretendentes e em sua racionalidade estratégica pensa uma forma de barrar o açodamento grosseiro deles. Hamilton (1992, p. 306) comenta: "De início, Penélope achou que conseguiria vencê-los pelo cansaço. Disse-lhes que só voltaria a casar-se depois que acabasse de tecer uma mortalha muito bela e primorosamente trabalhada para o pai de Odisseu, o velho Laerte, para que a já tivesse pronta no dia de sua morte. Os pretendentes tiveram que ceder diante de tão piedosa intenção, e concordaram em esperar até que o trabalho estivesse pronto. Na verdade, porém, a mortalha nunca terminava, pois Penélope desfazia à noite o que tecera durante o dia”.
} 
Liberdades e resistências: as ações de emancipação da mulher e a negação da violência

Os pressupostos dos relatos míticos sublinham expectativas de comportamento humano. Inclinam-se para designar elementos especulativos no pensamento masculino e elementos práticos no pensamento feminino, como se fosse possível dissociar dimensões que necessariamente estão imbricadas, pelo simples fato de que teórico e prático não se excluem. Ao contrário, se necessitam. $\mathrm{O}$ preconceito responde por esses papeis recortados, como se fosse possível ordenar o fazer humano nos estreitos limites das determinações de gênero, cujo patrocínio está nas vontades poderosas que tentam decidir sobre liberdade e racionalidade humanas.

Vemos, pois, que a resistência ao medo e a resistência pela ação, seja pelo trabalho e/ou pela ocupação do espaço público, situa a mulher em outro patamar de cidadania.

Nesta relação do espaço público e do trabalho, Alexandra Kollontai afirma que a mulher sofre adaptações associadas às transformações advindas com 0 capitalismo, e reitera:

O tipo fundamental da mulher está em relação direta com o grau histórico do desenvolvimento econômico pelo qual atravessa a humanidade. Ao mesmo tempo que se experimenta uma transformação das condições econômicas, simultaneamente à evolução das relações de produção, experimenta-se a mudança no aspecto psicológico da mulher. (KOLLONTAI, 1979, p. 45).

Esse aspecto psicológico avulta na mulher uma dimensão de maturidade política e econômica, capaz de fazê-la entender o sistema produtivo, para o qual ela contribui com sua mais valia. Resulta disso que a figura da mulher trabalhadora assalariada emerge no mundo do trabalho de uma nova forma, representando a força feminina de trabalho, com avaliação quantitativa rentável.

Adverte Alexandra Kollontai que a reação a essa figura feminina foi grande, por parte de posturas conservadoras, de modo que houve empenho desse conservadorismo para que a mulher voltasse ao lar, numa demonstração forte de atitudes reacionárias e ultrapassadas. Observemos que a autora demonstra nesse cenário, ambientado na Rússia do final do século XIX e primeiras décadas do século $\mathrm{XX}$, os momentos em que se agrava a situação.

Com isso, demarca que:

A mulher ameaçada de perder toda a assistência, diante do temor de padecer privações e fome, vê-se obrigada aprender a se manter sozinha, sem o apoio do pai ou do marido [...]. Dá-se conta, com assombro, de toda inutilidade do equipamento moral com que a educaram para percorrer o caminho da vida. As virtudes femininas passividade, submissão, doçura que lhe foram inculcadas durante séculos, tornam-se agora completamente supérfluas, inúteis e 
prejudiciais. A dura realidade exige outras qualidades nas mulheres trabalhadoras. Precisa agora de firmeza, decisão e energia, isto é, aquelas virtudes que eram consideradas como propriedade exclusiva do homem. (KOLLONTAI, 1979, p. 46).

Na verdade, Kollontai chama atenção para o fato de que a mulher, saída desse choque econômico-cultural, torna-se uma individualidade consciente de sua condição de classe capaz de saber o que deseja e demarcar seu território. Diferente daquelas mulheres que não vivem tal situação, as operárias sentem em si e no ambiente em que vivem o antagonismo de classe e são levadas a participarem, efetivamente, das lutas operárias.

Nas palavras de Kollontai (1979, p. 23):

O novo tipo de mulher, que é interiormente livre e independente, corresponde plenamente à moral que elabora o meio operário no interesse de sua própria classe. A classe operária necessita, para a realização de sua missão social, de mulheres que não sejam escravas.

Tais mulheres influenciaram a inteligência de suas contemporâneas, destaca a autora, e se tornaram insubmissas, destruindo velhos símbolos que oprimiram gerações inteiras. E escritores viram, nessa mulher moderna, uma nova mulher, que assume a própria luta.

\section{Em torno de expectativas}

É conhecida a peça grega de Sófocles, como também suas nuances, cujo enredo e desfecho leva-nos a refletir o que significa desafiar os donos do poder. Antígona, ao desafiar as leis da polis, enfrenta o soberano Creonte. Ela enterra o corpo do seu irmão Polinice, para evitar que seja devorado pelas aves de rapina. Esse gesto lhe custa a própria vida. Mais uma vez o mito nos mostra a resistência da mulher, na sua forma extrema. Enfrentar tiranos sempre significou correr riscos, ainda que, em nome de uma ética das normas, eles, os tiranos, estejam resguardados.

A dimensão democrática da vida social nos faz viver esse jogo de tensões entre as leis da polis (as normas do Estado) e as leis do oikós (a ética doméstica, as normas da vida privada). E isso se torna complexo, quando tiranos como Creonte, em nome do Estado forte, falam aos cidadãos com prepotência: "O homem que a cidade escolheu para chefe deve ser obedecido em tudo, quer seus atos pareçam justos, quer não”.

Pensamos que a questão do feminino, da feminilidade, do olhar da mulher sobre os fatos nas inter-relações pessoais, tem algo de extremamente singular. É a singularidade do subjetivo feminino, que, do seu ângulo pessoal, histórico, cultural, 
Liberdades e resistências: as ações de emancipação da mulher e a negação da violência

religioso, ideológico e político percebe o mundo e compreende, de sua maneira, tais questões. Essa apreensão é especial do gênero humano chamado mulher.

Nesse modo de ver, surge uma tese levantada por Simone de Beauvoir, "Ninguém nasce mulher, as pessoas se tornam mulher" ${ }^{4}$. Essa ideia envolve um conjunto de significados, nem todos transparentes. O tornar-se mulher faz parte do projeto subjetivo de conquistar espaços públicos num mundo moldado pelo masculino, tanto nas ideias quanto nas práticas sociais. É um enfrentamento cultural, em que a mentalidade de domínio dos homens procura se manter intocável, tanto nos direitos quanto nos deveres. Isso ocorre, especialmente, na esfera prática da vida, já sustentada pela leitura teórica dos que criam as normas e estabelecem os privilégios.

Do ponto de vista de uma sociedade estruturada a partir das características machistas, a mulher encontra um primeiro desafio: demonstrar, antes de tudo, sua honestidade e competência, em níveis máximos, o que não é exigido ao homem, na mesma intensidade e com o mesmo rigor. Aqui, estamos muito longe da questão superada de uma "guerra dos sexos". Estamos querendo discutir a possibilidade de que as pessoas sejam tratadas da mesma forma e com o mesmo respeito aos direitos pessoais e coletivos.

Não reivindicamos um lugar para a mulher, pelo fato de ser mulher. Pensamos no lugar público, no espaço da cidadania, que é o espaço do sujeito detentor de vontade e de liberdade. A mulher não precisa ser vista com "raridade" nestes espaços. Ela necessita, como qualquer pessoa, ser vista e entendida, como expressão de uma subjetividade, expressão essa feminina e masculina. E na busca de um espaço público, a mulher segue abrindo caminhos, muitas vezes, numa luta desigual. Essa é uma parte da história a ser percorrida com a convicção de quem conhece e busca pelos próprios direitos. Tal caminhada faz parte da conquista dos direitos dos oprimidos.

Assim, nossas ações de emancipação, negadoras da violência, exigem uma compreensão alargada dos processos de libertação feminina. Este não é um projeto unívoco, é um projeto coletivo. Não podemos nos sentir livres, enquanto os aprisionamentos sociais e econômicos mantiverem outras mulheres prisioneiras da barbárie, da ignorância, do vício, da segregação racial e da fome. Da mesma maneira, nossos úteros continuarão violados enquanto a violência persistir, sob as mais diversas formas.

Posto isto, queremos acreditar que as pessoas sérias estão preocupadas com a construção de uma vida ética, fundamentada nas razões que levam os sujeitos a viverem coletivamente. Terá que ser construída uma ética social, alicerçada no

\footnotetext{
${ }^{4}$ BEAUVOIR, Simone de. Balanço Final. Rio de Janeiro: Nova Fronteira, 1990, p. 486. Essa frase, já fora escrita pela autora em $\mathrm{O}$ segundo Sexo, obra com características autobiográficas.
} 
PIRES, C.

querer coletivo, querer de mulheres e homens; mulheres e homens sujeitos de uma razão ética; mulheres e homens construtores de novos caminhos comuns; mulheres e homens esperançosos na linguagem da inteligência, que lhes permitirá a busca de espaços de luta, sem violência, sem dominação.

\section{Referências}

BEAUVOIR, S. Balanço final. Rio de Janeiro: Nova Fronteira, 1990.

CHAGAS, E. P. Corpo feminino do detalhe... uma possibilidade de construção de novos territórios para a subjetividade feminina. In: ROMERO, Elaine (org.) Corpo, mulher e sociedade. Campinas, SP: Papirus, 1995.

GEBARA, I. "Entrevista", in IHU: Revista do Instituto Humanitas/Unisinos. São Leopoldo, RS, 2007, p. 7-8.

HAMILTON, E. Mitologia. São Paulo: Martins Fontes, 1992.

KOLLONTAI, A. A nova mulher e a moral sexual. São Paulo: Global, 1979.

PERROT, M. Os excluídos da História: operários, mulheres, prisioneiros. São Paulo: Paz e Terra, 1992.

PIRES, C. "Estética do silêncio: a tessitura do manto de Penélope", In: Ethica. Cadernos Acadêmicos. Universidade Gama Filho. Rio de Janeiro. 2005. v. 12, n. 1 e 2. p. 177-186.

Submissão: 20. 02. 2019 / Aceite: 30. 03. 2019 